\title{
The Next 20 Years of Hospital Medicine: Continuing to Foster the Mind, Heart, and Soul of Our Field
}

\author{
Andrew D. Auerbach, MD, MPH*
}

Department of Medicine, UCSF School of Medicine, San Francisco, California.

In 1995 I took my first job as a hospitalist at a community teaching hospital where hospitalists, though then known as "medical directors," had been in place for 20 years. Soon afterward, our field gained a name, and my old job no longer was mistaken for a utilization review functionary or lead of a medical unit.

I have been lucky enough to have seen the field of hospital medicine grow rapidly in scope and importance. The growth of our specialty in mere numbers alone is a testament to the value we in hospital medicine (MDs, DOs, PAs, NPs) bring to the care of acutely ill patients. We are the front line caring for the elderly and vulnerable, the glue holding transdisciplinary care teams together, and lead hospitals, health systems, and governmental organizations. Hospitalists touch the lives of our patients, and shape the health systems' practices and health policy on a national and international scale. These are remarkable achievements for a field which, just a few years ago, was concerned about becoming a job equivalent to perpetual residency training (or worse) and gained only grudging acceptance. ${ }^{1}$ There is no doubt that the roles of hospitalists will continue to evolve, and whereas hospitalists will be able to shape the debates and development of new programs solving the problems of our health systems, we must take time to foster the mind, heart, and soul of our field.

When I speak of the mind of hospital medicine, I am thinking of our field's contribution to the evidence for how to care for patients' illnesses, a different body of knowledge than our field's focus to date on hospitals and health systems. Hospital medicine has been growing research capacity at a rate that is slower than the field overall, a problem in part due to limitations in National Institutes of Health funding for fellowships and early-career awards, which in turn has restricted the pipeline of young and innovative researchers. Slow growth may also be a result of an emphasis on health systems rather than diseases. ${ }^{2}$ I and others have written about the need to create mentoring support for junior research faculty as a way to

*Address for correspondence and reprint requests: Andrew D. Auerbach, MD, MPH, Department of Medicine, UCSF School of Medicine, 533 Parnassus Avenue, UC Hall, San Francisco, CA 94143-0131; Telephone: 415-502-1412; Fax: 415-514-2094; E-mail: ada@medicine.ucsf.edu

Received: June 3, 2016; Accepted: June 3, 2016 2016 Society of Hospital Medicine DOI 10.1002/jhm.2631

Published online in Wiley Online Library (Wileyonlinelibrary.com). promote success and avoid burnout, ${ }^{3-7}$ and while at least 1 hospital medicine research network exists, ${ }^{8}$ there is room for many more. However, at its core, our specialty needs to devote more time and focus to becoming a full scientific partner with our colleagues in cardiology, pulmonary medicine, and critical care, among others. To develop the mind of hospital medicine we will also need to think about our contributions to useful clinical guidelines for care of diseases and patients. Developing trustworthy clinical guidelines can be time consuming ${ }^{9}$ but is a key part of ensuring patients and families understand the rationale for changes in clinical care. Hospital medicine as a field has been a leader in programs that develop approaches to implementing evidence and stands in an excellent position to-perhaps in collaboration with other specialties-create the next-generation guidelines that are practically minded, evidence based, and end up being used.

The heart I speak of is how we can make sure that the field of hospital medicine is one that is attractive and sustainable as a career. Electronic health records' impact on day-to-day work is substantial and a large part of the problem, though a more fundamental problem we face is in how to create sustainable jobs at a time where we are going to need to deliver higher-value care to more patients with the same number (or fewer) providers. This is an issue that means we need to settle many important aspects of our work-pay, relationships with our peers, control over our work on a day-to-day basis, hospitalists' work schedules (such as the 7 days on/7 days off model)_while we also grapple with how to work within a population-health framework. I am not prescient enough to see all the solutions to burnout, but there are at least 2 opportunities hospitalists are perhaps best suited to develop and lead. The first is how we arrange our teams in the hospital and afterward. Recent articles have talked about how medicine needs to be open to Uber-like disruptive models, ${ }^{10}$ where labor is deployed in fundamentally different ways. Tools such as e-consults, the application of population health tools to inpatient care, telemedicine, or some forms of predictive analytics may be examples of these tools, which are routes to allowing more care to be delivered more effectively and more efficiently. Another opportunity lies in how we adapt our electronic health records to our work (and vice versa). The perils of "sloppy and paste" documentation are 
indicative of the burden of busywork, the pressures of needing to focus on revenue rather than clinical utility, and exhaustion; hospitalists are well positioned to think about how-as payment reform continues to evolve-documentation can be less busywork and more clinically useful, patient oriented, and shareable across sites and phases of care.

Now to the soul of our field. Hospital medicine has rightly been considered a key partner in developing the solutions hospitals and health systems need to address gaps in quality, safety, value, and clinical outcomes. However, this self-image of hospital medicine has the downside of being viewed as doctors for hospitals, rather than doctors for patients and families who are in hospitals. As we think about burnout and jobs that are fulfilling and meaningful over the long term, I increasingly return to the factors that motivated me and many others to become physicians: meaningful relationships with patients, being an excellent clinician, and making a lasting contribution to my community through my patient care, support of my colleagues, and teaching younger physicians. It is easy for the pressures of the hospital and need to fix problems rapidly to obscure these larger motivators, but our field will need to ensure that these elements remain how we prioritize and shape our field going forward. Hospital medicine is comprised of physicians who do clinical care and who in most cases entered the field for that reason alone. Using the true north of improving and innovating care in ways that impact patient lives-not just the needs of our hospitals-in meaningful ways will need to be the soul of our field, and will allow the mind and heart of hospitalists and hospital medicine to thrive.

\section{References}

1. McMahon LF Jr. The hospitalist movement-time to move on. $N$ Engl J Med. 2007;357(25):2627-2629.

2. Goldman L. An intellectual agenda for hospitalists: lessons from bloodletting. J Hosp Med. 2013;8(7):418-419.

3. Reid MB, Misky GJ, Harrison RA, Sharpe B, Auerbach A, Glasheen JJ. Mentorship, productivity, and promotion among academic hospitalists. J Gen Intern Med. 2012;27(1):23-27.

4. Sehgal NL, Sharpe BA, Auerbach AA, Wachter RM. Investing in the future: building an academic hospitalist faculty development program. J Hosp Med. 2011;6(3):161-166.

5. Harrison R, Hunter AJ, Sharpe B, Auerbach AD. Survey of US academic hospitalist leaders about mentorship and academic activities in hospitalist groups. J Hosp Med. 2011;6(1):5-9.

6. Glasheen JJ, Misky GJ, Reid MB, Harrison RA, Sharpe B, Auerbach A. Career satisfaction and burnout in academic hospital medicine. Arch Intern Med. 2011;171(8):782-785.

7. Flanders SA, Centor B, Weber V, McGinn T, Desalvo K, Auerbach A. Challenges and opportunities in academic hospital medicine: report from the academic hospital medicine summit. J Gen Intern Med. 2009;24(5):636-641.

8. Auerbach AD, Patel MS, Metlay JP, et al. The Hospital Medicine Reengineering Network (HOMERuN): a learning organization focused on improving hospital care. Acad Med. 2014;89(3):415-420.

9. Greenfield S, Steinberg E, Avorn J, et al. Clinical practice guidelines we can trust. National Academy of Sciences website. Available at: http://www.nationalacademies.org/hmd/Reports/2011/Clinical-Practice-Guidelines-We-Can-Trust.aspx. Published March 23, 2011. Accessed May 20, 2016.

10. Detsky AS, Garber AM. Uber's message for health care. N Engl J Med. 2016;374(9):806-809. 